\title{
Fertility Postponement between Social Context and Biological Reality: The Case of Serbia ${ }^{1}$
}

\author{
Petar Vasić ${ }^{2}$ \\ Faculty of Geography, University of Belgrade, Serbia
}

\begin{abstract}
Fertility Postponement between Social Context and Biological Reality: The Case of Serbia. This paper reflects some views on the biological background of fertility tempo and its demographic consequences. Assumptions are tested on Serbian fertility data, based on deductive conclusions and by applying the demographic method. Due to decreasing odds for conception as well as for a live birth pregnancy outcome with a woman's age, the changing of the age-pattern of fertility in Serbia has led to fewer births, and has revealed the negative influence of a dispersion of births outside of an optimal reproductive age on fertility rates. This article summarizes findings about social context of fertility postponement and agerelated infertility in women and clarifies the biologically driven demographic consequences of childbirth postponement on the total number of births and total fertility rate.

Sociológia 2021, Vol. 53 (No. 3: 309-336)

https://doi.org/10.31577/sociologia.2021.53.3.12
\end{abstract}

Key words: Childbirth postponement; total fertility rate; mean age at birth; fertility tempo; infertility; success rate; desired number of children; fertility tempo policies; Serbia

\section{Introduction}

The mechanisms of the childbirth postponement, mostly explained by economists or sociologists, were understood as rational based decisions of individuals (or couples) trying to cope with the requirements of modern society. In Western, Southern and Northern Europe as well as Japan, the mean age of first-time mothers reached around 28-29 years in 2008, an increase of 45 years when compared with the 1970's (Schmidt et al. 2012). These mechanisms explained by income and consumption rationale (Becker 1965; Modigliani - Brumberg 1980), or by liberal and postmodern values (Van de Kaa 2001; Lesthaeghe 2010), barely mention physiological limitations to the individual choice. These limitations given by the human species reproductive span, with no exception, affect all trying to make an optimal reproductive choice, independent of social norms or historical context. Social, economic, psychological and other causes of fertility postponement, understood as continuous increase in mean age at birth (MAB), are well explained by numerous theoretical frameworks and documented by empirical exercises. The core idea of this article is not to debate on possible causal mechanisms of

\footnotetext{
1 Acknowledgements: This research is the result of previous work on the project Researching Demographic Phenomena for the Purpose of Public Policies in Serbia (47006) which was closed in 2019. and was financed by the Ministry of Education and Science of the Republic of Serbia.

2 Address: Dr. Petar Vasić, Assistant Professor, Faculty of Geography, University of Belgrade, Studentski trg 3/III, 11000 Belgrade, Serbia. E-mails: vasic.dem@gmail.com and petar.vasic@gef.bg.ac.rs
} 
fertility postponement, but to provide the methodological tool for understanding the direct demographic consequence of such postponement. However, demographic effects of fertility postponement can't be well understood and, consequently, measured outside its societal context. For a long period, life in Serbia was marked by societal crisis and a large number of turbulent events such as disintegration of the SFR Yugoslavia, economic sanctions, large inflow of refugees, the NATO bombing, etc. (Vasić - Marinković 2016). Specific internal conditions led to an early decline in fertility, which potentiated negative demographic momentum. These sociologically driven changes in agepattern of fertility consequently led to a fertility decrease attributable to agerelated increase in infertility and adverse pregnancy outcomes. The influence of fertility postponement on completed cohort fertility and childlessness, itself, is hard to quantify. When fertility rates are declining, it is methodologically difficult to distinguish what share of that decline could been attributed to infertility due to postponement and what share surely would have occurred because couples intended to have fewer children (Schmidt et al. 2012), leading us to try to identify the number of attempts/couples/women trying to conceive during a certain year/age. The largest issue is to define age-specific probabilities for positive reproductive outcome (success probability curve) so to measure the age-effect. We will explain fertility transition in Serbia, its specific path, unlike the other post-communist countries and, based on the aim of the paper, to provide firm argument for introducing of an age-variable in fertility policy.

\section{Aim of the paper}

Fertility tempo-effect can be explained as the 'amount' of births shifted to the next year due to the rise of mean age at birth (MAB), or opposite, the additional amount of births packed into the single year due to the lower MAB (Bongaarts - Feeney 1998). We will try to test the hypothesis that MAB increase alone, may not be the only reason causing tempo-effect. Change of the fertility age-pattern can cause tempo-effect even without the change of MAB. Age-related changes in fecundity, infertility ${ }^{3}$, and pregnancy outcome significantly alter quantum of realized fertility, so the distribution of conception attempts across the fertile age will determine overall fertility success rate even without MAB change. The aim of this article is to establish methodological tool for quantification of crude tempo-effect arising from the biological constraints, independent of social norms and historical context. Surely, social (and other) factors can amplify or diminish the influence of biological factors through the change of the age-pattern of fertility. During the demographic

\footnotetext{
${ }^{3}$ The usual medical definition of infertility/subfertility is when a couple fails to conceive after 12 months of trying.
} 
transition, modern societies did their best to diminish the biological conditionality of the demographic change, and to move away from natural patterns of dying and reproduction. Paradoxically, societies at the other end of the demographic transition, are facing increasing biological conditionality of the demographic change through the bottleneck of fertility. Well known models by Becker (1965) and Easterlin (1969) postulated the demand for children as the bottleneck of fertility, and they were right. However, constant childbirth postponement is further narrowing the bottleneck of fertility. Contemporary fertility postponement became so severe in the below-replacement populations that, besides social, economic, and psychological obstacles between desired and achieved number of children (fertility gap), biological obstacles are on the rise too. Finally, the aim of the paper is to quantify the effect of change in the agepattern of fertility on the total number of births and total fertility rate (TFR).

\section{Fertility postponement and reproductive outcomes - literature overview}

In the last 50 years across Europe, MAB has been rising mostly as the result of a fertility decline among young women, which was followed by fertility increase among women aged 30+, although, some recent studies hypothesize that these two are substantially separated and independent processes (Beaujouan - Toulemon 2021). Fertility postponement, embodied through the changes in the age-patterns of births, in particular of first births, reflect numerous changes in employment and education patterns, availability and affordability of housing for the young, changes in value systems and social norms, etc. Postponement of first births is particularly important because it shifts higher order births to ages of lower fecundability, increasing the chances for lower fertility (Frejka - Sardon 2006). The main drivers of fertility postponement are delayed completion of education, the rise of effective contraceptive methods, liberal abortion laws, spread of childless cohabitations, and professional aspirations. Besides these factors, Ron Lesthaeghe (2001) listed several main drivers of fertility postponement for developed European countries: longer education and women's economic authonomy; high materialism and the need for double income family; higher male and female human investment; personal identity and high divorce risk; selffulfilment and freedom of choice; a greater stress on the quality of life with a rising taste for leasure; and an open path for the future. Also, the choice not to have (additional) children, which is recognized as 'ecological' and 'socially-responsible' reproductive decisioning, is on the rise, albeit marginal in contemporary Serbian society. Macro factors are determining overall 'social climate' which represents suitable background for fertility postponement, but at the individual level, final reproductive decisions are made by couples (or singles) primarilly regarding personal context. The recent economic recession has identified the times of 
crisis as incompatible with marriage and childbearing (Sobotka et al. 2011). Business cycles undoubtly contribute to the fertility fluctuations in the posttransitional societies, especially through fertility downturns in uncertain times (Sobotka 2017) and vice versa. In addition to the well known theories, new paradigms tackle micro aspects of partnership and parenthood, and can explain fertility postponement in a more subtle way (Bobić 2018).

Independent of all the micro and macro drivers of fertility postponement, there are strongly inherited norms accross all of Europe which are opposed to 'endless' fertility postponement, seting the age from which a person should no longer have additional children at 46 for men, and 41 years of age for women. A healthy mother, supportive partner, and the health of the father, are set as the most important parenthood preconditions in the EU-25 (Testa 2007), indirectly bringing the age-factor as very important on an individual level through the health status. Due to efficient contraceptives, people can now have children at older ages after not having them when they are young, thus increasing the likelihood of renouncing or having difficulty in having children later. Widespread fertility decline at young ages across Europe resulted in the simultaneous increase in MAB and decline in TFR (Beaujouan - Toulemon 2021). The longer the first birth delay, the higher the odds for childlessness and the smaller number of children at older ages (Beaujouan et al. 2019; Habbema et al. 2015). With rising age, the chances for positive reproductive outcome are becoming smaller due to increased sterility, infertility, and adverse pregnancy outcomes. In all women at pregnancy risk, the livebirth, as a reproductive outcome, is a highly age-related result of mutual influences of these interrelated spontaneous factors/restrictions.

The first biological constraint/restriction to fertility would be permanent sterility. GGS data for many European countries indicate that many people intend to have children during age-periods with increased risk of reproductive failure (Schmidt et al. 2012). The basic physiological frame for reproduction, called fecundity, denotes biological capacity to reproduce (Baird - Strassmann 2000). Adversely, permanent sterility can be defined as the definite inability for conception. The incidence of sterility increases as the age of the female partner increases. Although, the true incidence of sterility is difficult to determine because of non-reproductive factors such as voluntary childlessness, population studies can provide some insight (Liu - Case 2011: 1169). In one study of 7 populations with rare premarital conceptions and contraception use, the percentage of childless women was higher in those who married later (Menken et al. 1986; according to Liu - Case 2011) implying a clear age-related rise in sterility. The prevailing concept of fecundity decline assumes that the agedependent loss of fertility is determined by the continuous depletion of the pool of oocytes stored in both ovaries during fetal life, leading to a decrease of 
fertility and its subsequent expiration (Eijkemans et al. 2014). Based on six natural fertility populations comprising 58,051 eligible women, the age-curve showed that the share of permanent sterile women increased from $3 \%$ at the age of 20 , to the $12 \%$ at age 35 years and it rises rapidly to about $50 \%$ at age 41 , and approaching $100 \%$ at the 50 years of age. The distribution of ages at the last birth (ALB) was remarkably similar among different historical periods and in the age-pattern of women seen in ART treatment, which denotes highly age-related pattern independent of social and historical context. The pace of biological clock ticking is a strongly heritable process, so it cannot change significantly within such a short time-period (Eijkemans et al. 2014).

The second restriction to the fertility would be infertility, ie. the share of infertile women out of all fecund women trying to conceive. However, setting these restrictions in this way may be inconvenient as we can't know which share of women trying to conceive is permanently sterile, and which share of them is actually infertile. Some couples may be classified as clinically infertile based on not conceiving after a year or more of unprotected intercourse, but it's unlikely that they will be unable to conceive a pregnancy naturally at all (Dunson et al. 2004). Studies on sterility are carried out exclusively on women who haven't reported any medical conditions regarding infertility or conception problems (Liu - Case 2011; Schmidt et al. 2012; Dunson et al. 2004; Wesselink et al. 2017; Steiner - Jukic 2016). Yet, we can't be sure if there are women trying to conceive for the first time so it is obvious that they haven't experienced any fertility problems yet. The fact that using sterility and infertility restriction may cause doubling of sterility restriction forces us to use solely infertility restriction. Some studies on donor insemination, performed in couples with severe male infertility, confirm an age-related decline in pregnancy rate - PR. This can be considered as a good reflection of female fertility because other non-reproductive factors are removed. Liu and Case (2011) have found that a negative effect on PR is seen in women above the age of 30 , and is even more pronounced for women above the age of 35 . One study of almost 3000 cycles showed cumulative PR of $62 \%$ for women below 30 years of age, and $44 \%$ for women aged 30+ years after 12 cycles (Doyle et al. 1993; Virro - Shewchuk 1984; according to Liu - Case 2011). Results in numerous studies examining 12-months' PR are showing very similar pattern. Within 12-months, almost $90 \%$ of 20-28-year-old women, but only $75 \%$ of women around the age of 35 had achieved pregnancy (Schmidt et al. 2012), and according to Dunson et al. (2004) women aged 19-26 years achieved 92\%, women aged 27-34 years 86-87\%, and women aged 35-39 years achieved $88 \%$ pregnancy during one year. Steiner and Jukic (2016) have found that the average PR was $78 \%$, and dropped from $87-88 \%$ to $48 \%$ with women's age, and Wesselink et al. (2017) found that cumulative PR at 12 cycles of attempt- 
time ranged from $79.3 \%$ (age 25-27 years old) to 55.5\% (age 40-45 years old). Age-associated infertility appears to be primarily related to ovarian aging, with the female age as the only realistic information about it (Liu - Case 2011; Eijkemans et al. 2014; Leridon 2004; Dunson et al. 2004).

PR is highly related to women's age, but also to the male partner's age. Previous studies represented data with the prevailing aim of explaining the effect of female aging on achieving pregnancy. Other studies show the effect of male age on achieving pregnancy during the 12-month time frame. Increasing male age is associated with infertility and time to pregnancy (TTP), whether the age at conception or at the onset of attempting to achieve pregnancy was used in the analysis (Kidd et al. 2001).When analyzing age-specific PR, Wesselink et al. (2017) is pointing that similar patterns were observed among male patients, although with weaker age-relation. Ford et al. (2000) reported that men 35+ years of age had twofold subfecundity comparing with men below 35. Liu and Case (2011) found that sperm parameters decrease with age, and that conception odds decrease $3 \%$ per year. Analysis of the impact of male age on women's PR showed the decreasing odds even when controlled for the woman's age, when compared with the age group to 24 years. Probability for a conception within 12-months leading to a birth decreased by $3 \%$ per year of increasing male age, starting from the age of 25 (Ford et al. 2000). In couples in ART threatment, each year of male age, reduced the probability of achieving a livebirth for approximately $4 \%$, when controlled for female age (Pinborg et al. 2011). Among 35-year-old women, the proportion of couples failing to conceive within 12 cycles increases from $18 \%$ if the male partner is 35 years old in comparison to $28 \%$ if the male partner is 40 (Dunson et al. 2004).

Fetal loss is the last restriction that can prevent fertility. Out of all achieved pregnancies not all of them will result in a livebirth. Miscarriage rates, the risk of an ectopic pregnancy, stillbirth and spontaneous abortion increased with increasing maternal age (Steiner - Jukic 2016; Nybo-Andersen et al. 2000), both after natural or assisted conception (Schmidt et al. 2012). The fall in LR following ART cycles is even steeper with age: $40 \%$ of non-donor ART cycles initiated at ages $<35$ resulted in livebirth in 2013 , compared with $17 \%$ of the cycles initiated at age 40 and $2 \%$ at ages $45+$ (Beaujouan - Sobotka 2017). Micarriages remain relatively stable up to a maternal age of 35 years, and increase from age 35 to age 40 from around 15 to $30 \%$, and a rate of $50 \%$ is reached at around 42 years of age (Schmidt et al. 2012). Miscarriage rate grew from $13.6 \%$ at age $25-29$, to $16.0 \%$ at age $30-34,20.0 \%$ at age $35-39$ and $27.0 \%$ at age $40-44$ (Leridon 2004). The risk of fetal loss according to maternal age at conception followed a J-shaped curve, with a steep increase after 35 years of age. More than one fifth of all pregnancies in 35-year-old women resulted in fetal loss, and at age 42 more than half of the intended pregnancies 
(54.5\%) resulted in fetal loss, $8.9 \%$ in women aged $20-24$, and even $74.7 \%$ in those aged 45+ (Nybo-Andersen et al. 2000).

\section{Post-transitional fertility in Serbia}

Serbia (without Kosovo and Metohia) is dealing with below-replacement fertility since the mid-1950s. The net reproduction rate has been below 1 since 1956 (Penev 2001), but the relatively young population until the end of 1980's resulted in positive natural increase by 1992 (Vasić - Marinković 2016). Since then, the negative natural increase rose to almost 53 thousand people in 2020. Analysis of women born between 1930 and 1962 has reported that none had fertility above replacement (Rašević 2015), and probably no generation of women born after the WWI (Penev 1995).

Serbia has faced below-replacement fertility very early, but also the longterm persistence of cohort TFR at 1.8 children per woman. Accelerated socialistic modernization after WWII, industrialization and urbanization, rural to urban migrations, family transformation, women's full-time employment, liberalization of abortion, and slow but continuous increase in personal consumption and incompatibility of work and family (Bobic 2018), are the main reasons which contributed to the growth of economic and psychological cost of parenthood (Rašević 1995). The trend of increasing share of childless women of an optimal fertile age (20-34 years) was registered since 1981, and according to the latest census (2011), almost one in three women from the agecohort 30-34 were childless (30.6\%) (Rašević 2015).

Since 1970, period TFR was stable at $15 \%$ bellow-replacement in the following two decades, with no tendency to increase, as in Eastern European countries, or further decline, as in Western European countries. After that, during the 1990's, TFR was on the constant decrease from 1.73 in 1991 to 1.40 in 1999. Since 2000, TFR ranged between 1.37 as registered in 2007 and 1.51 as recorded in 2019. During the 2000's, period MAB increased from 26.5 to 30.1 years of age.

In Serbia untill the end of the 1990's, as in other Eastern European countries, relatively high fertility among young was followed by low levels of total fertility. The increase in childbearing of older women was just starting in the 1960's birth cohorts in the same time with relatively high fertility of young women still existing. In the post-communist countries fertility postponement has been a relatively recent phenomenon (Frejka - Sardon 2006). For the women aged 36+ the average number of livebirths at the time of the 2011 Census showed clear downward trend from 1.81 in 1963 generation to 1.55 in 1975 generation. Although younger cohorts still have a chance to recuperate, it is possible to predict the cessation of stabilization in completed fertility (Rašević 2015). Also, in the age cohort of 40-49 years, $11.8 \%$ of women in 
Serbia were childless at the time of the 2011 census comparing to the $8.8 \%$ in the 2002 census. Bearing in mind that women in Serbia relatively rarely give birth after the age of 40, it clearly indicates increasing childlessness among generations born in mid-1960's and younger. Today in Serbia, even when they give birth to a first child, women face a critical transition moment to a second child, and the newest research find experiences of 'first baby stage' as an important for low completed fertility, explained by high socio-psychological costs of women/mothers and the asymmetry in gender roles at the start of (and later) parenthood (Bobić 2018).

Newest fertility change in Serbia, characterized by substantial fertility postponement was carried out by generations of women born in mid-1970's and younger as in other post-communist countries (Frejka - Sardon 2006; Vasić et al. 2014). Fertility in these countries fell due to the curbing of second birth risk and second birth postponement to the advanced ages. Forerunners of this shift were higher educated ones, with university degree, which expect to get employed after completing their education, postponing parenthood until she and her partner achieve secure employment because of incompatibility of private and professional sphere (Zeman et al. 2018; Sobotka 2017), which becomes dominant economic-reproductive behavior in Serbia too (Vasić 2017). Like in other socialistic countries, female emancipation in Serbia had been achieved only partly and in a public sphere, without any major progress within the household (Bobić 2018). Countries, that practice relatively advanced economic development and low level of gender equity are oftenly characterized by low or declining fertility (Sobotka 2017). High socio-psychological costs of parenthood, and social crisis in Serbia during 1990's, combined with strongly valuated parenthood norms (Bobić 2018) resulted in some children early in life, but fewer overall (Beaujouan - Toulemon 2021). On the other hand, prolonged (even blocked) transition to adulthood in Serbia is more alike to the one in Mediterranean and less alike as in other post-communist countries, determined with a prolonged education, economic and housing issues, high unemployment, and strong family ties, resulting in a high share of young people still living with parents well into their 30's (Sobotka 2011; Stanojević 2013).

\section{Methodology}

The main idea of this paper is that fertility in the final stage is determined by age-related biological constraints. In couples at risk (with the unprotected sexual intercourse), with or without intentional positive reproductive decision, only the biological barriers can prevent fertility. The simple example for measuring age-effect would be as follows: if we have 1000 women trying to get pregnant during the year, then we may presume that not all of them will succeed. Then, if, let's say, 50 out of 1000 women are permanently sterile, we 
would have 950 women who are able to conceive. Out of the 950 women left, a certain number will turn out to be infertile (won't conceive within one-year time-frame). Here we come to the male partner, who may also turn out to be infertile. So, for example, 820 out of the starting 1000 women will get pregnant during one year, but not all pregnancies will result in a livebirth. And then, for example, we come to 750 livebirths out of 1000 women trying to conceive during the year, and we will call that ratio SR, representing age-related biological constraints - age-effect. One of the main assumptions, that the SR is highly age-related and common to all women regardless of ethnicity and race, have been confirmed through numerous sudies (Eijkemans et al. 2014: 2; Dunson et al. 2004; Maeda et al. 2014: 1340). SR is the result of four restrictions, shrinking the corpus of women aiming towards livebirth in following way:

1. share of fecund women out of women trying to conceive (fecundity rateFR), to exclude permanent sterility,

2. share of fertile women out of fecund women trying to conceive (pregnancy rate-PR), to exclude female infertility/subfertility,

3. share of fertile men trying to impregnate their partners (impregnation rateIR), to exclude male infertility/subfertility, and

4. share of livebirths out of all pregnancies (livebirth rate-LR), to exclude fetal loss.

Figure 1: Success rate scheme

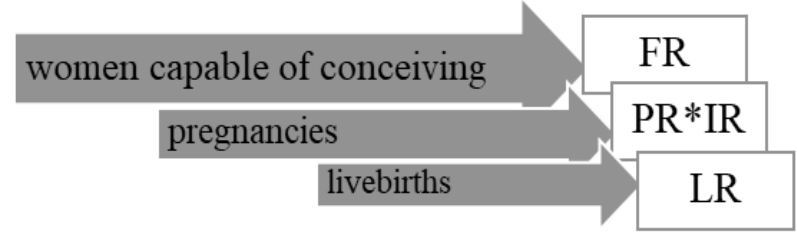

Chances for positive reproductive outcome are shrinking with age, but there is no consensus about the exact time-point of measuring SR. We have three potential time-points of measuring: point of accession - starting attempts to conceive, moment of conception, and moment of labor. As we have the different ages of a woman in each point, we decided to take the age at conception (age at childbirth minus 9 months) as a satisfactory assessment between accession point and the moment of labor. Estimation of age at accession can be very difficult because it's affected by TTP which we can hardly estimate due to the indirect concluding, and the only precise moment we have is the moment of labor, by which we can be sure about the time-point of conception (minus 9 months). In the end, time-point of conception is in between the point of accession and the moment of labor, so we can consider it a 
quite suitable intermediate for this purpose, usualy used in studies of an agerelated sterility/fecundity (Eijkemans et al. 2014). The equation for adjusting labor-age data to conception-age is based on the assumption of a roughly uniform distribution of births during one year, thus we can say that $3 / 4$ out of all births during the year were conceived in the year prior to the labor. We can calculate our restriction rates as in equation 1 , and apply this on all three quantities.

Equation 1: Rate ${ }^{4}$ adjustment to conception age

$\operatorname{adj} R_{x}=R_{x} \cdot 0.25+R_{x-1} \cdot 0.75$

As we have discussed the potential issue regarding sterility restriction, we will use only female and male infertility, and fetal loss restrictions to calculate SR. Female infertility will be introduced as a pregnancy rate (PR), i.e. share of women succeeded to get pregnant during 12 months of trying, out of all women trying to conceive, including (eventually) permanent sterile women too (encompassing sterility restriction). Male infertility will be presented using impregnation rate (IR) representing male capability to impregnate female partner of age $\mathrm{x}$ within 12-month time-frame. Last restriction - fetal loss, will be introduced by the share of the livebirths out of all achieved conceptions/pregnancies - livebirth rate (LR). Finally, age-specific SR adjusted to conception time-point would be the result of multiplication of these three quantities: adjusted PR, adjusted IR, and adjusted LR (Equation 2).

Equation 2: Success rate adjusted to conception age

$$
\operatorname{adj} S R_{x}=\operatorname{adj} P R_{x} * \operatorname{adj} I R_{x} * \operatorname{adj} L R_{x}
$$

The product of $\operatorname{adj} P R_{x}$ and $\operatorname{adj} L R_{x}$ solely can be considered as female factor. All rates are given by woman's age, even $\operatorname{adjI}_{x}$ as the male factor, thus forcing us to identify average age-difference within parental dyad in Serbia. It is common in western (Christian) cultures that the male partner is a bit older than a woman. Men have delayed having children to an extent similar to women and remain on average about 3 years older than women when having a child (Schmidt et al., 2012), which stands for Serbia too. On average 3-year older male partner have showed as remarkably persistent model when speaking about marriage and procreation in Serbia. According to 1900 census, the average age of the husband was 39.5 and of the wife was 35.9 leading to a 3.6year age-difference (State Statistics Administration of Kingdom of Serbia 1905). It is very indicative that the latest available ${ }^{5}$ age-difference between men

\footnotetext{
4 Equation is showed as general example for adjustment procedure, where $\mathrm{R} x$ means age-specific rate

${ }^{5}$ Age of the father was collected and statistically processed only until 2010 year.
} 
and women when having a child in Serbia is still similar (3.8 year older men on average) after more than a century. Also the average age-difference between partners in non-marital unions is slightly above 3 years (Statistical Office of the Republic of Serbia, 2017). Age-difference between parents (Table 1) is smoothed using parabolic function (Equation 3), and values are shown in Table 2. By the identification of the age-specific (measured by woman's age) age-difference within parental dyad in Serbia, we have the average male partner age, and then we simply apply age-specific (by male age) IR. Some findings say that the odds of conception decrease 3\% per year (Liu - Case 2011) from the age of 25 (Ford et al. 2000), and others say each year of

Table 1: Average age of the father by the age of mother at childbirth

\begin{tabular}{|c|c|c|c|c|c|c|c|c|c|c|c|}
\hline $\begin{array}{l}\text { Age of the } \\
\text { mother }\end{array}$ & 2002 & 2003 & 2004 & 2005 & 2006 & 2007 & 2008 & 2009 & 2010 & Average & $\begin{array}{l}\text { Age di- } \\
\text { fference }\end{array}$ \\
\hline $15-19$ & 25.0 & 25.0 & 24.9 & 25.0 & 24.9 & 24.7 & 24.9 & 24.8 & 24.8 & 24.9 & 7.4 \\
\hline $20-24$ & 27.5 & 27.5 & 27.5 & 27.8 & 27.8 & 27.8 & 27.7 & 27.9 & 28.0 & 27.7 & 5.2 \\
\hline $25-29$ & 30.8 & 30.8 & 30.9 & 31.0 & 31.1 & 31.1 & 31.1 & 31.1 & 31.2 & 31.0 & 3.5 \\
\hline $30-34$ & 34.7 & 34.5 & 34.5 & 34.7 & 34.7 & 34.6 & 34.7 & 34.8 & 34.7 & 34.7 & 2.2 \\
\hline $35-39$ & 39.0 & 39.0 & 42.4 & 39.1 & 38.9 & 38.9 & 38.8 & 38.6 & 38.5 & 39.2 & 1.7 \\
\hline $40-44$ & 42.5 & 42.2 & 43.2 & 42.7 & 46.0 & 43.0 & 42.6 & 42.5 & 42.5 & 43.0 & 0.5 \\
\hline $45-49$ & 43.4 & 42.2 & 44.6 & 40.8 & 43.2 & 45.0 & 44.2 & 44.9 & 45.7 & 43.8 & -3.7 \\
\hline $50+$ & 38.6 & 39.4 & 40.8 & 30.3 & 39.8 & 34.2 & 37.3 & 42.5 & 41.8 & 38.3 & -11.7 \\
\hline $\begin{array}{l}\text { Average } \\
\text { age of the } \\
\text { father }\end{array}$ & 30.8 & 30.8 & 31.2 & 31.2 & 31.4 & 31.4 & 31.6 & 31.8 & 32.0 & 31.4 & \\
\hline $\begin{array}{l}\text { Average } \\
\text { age of the } \\
\text { mother }\end{array}$ & 26.9 & 27.0 & 27.3 & 27.3 & 27.5 & 27.7 & 27.9 & 28.2 & 28.5 & 27.6 & \\
\hline $\begin{array}{l}\text { Average } \\
\text { age di- } \\
\text { fference }\end{array}$ & 3.9 & 3.8 & 3.9 & 3.9 & 3.9 & 3.7 & 3.7 & 3.6 & 3.5 & 3.8 & \\
\hline
\end{tabular}

Source: Authors calculations based on data from Demographic yearbook of Republic of Serbia $2002-2010$

increase in male age, is reducing the probability of achieving a live birth by approximately 4\%, when controlled for female age (Pinborg et al. 2011), that is by $2.5 \%$ (Dunson et al. 2004). According to these findings, we have decided to use a median value of $3 \%$ annual decrease to calculate IRx, and to consider IRx in men younger than 25 as a maximum when controlled for woman's age, thus to set it at $100 \%$. 
Figure 2: Age difference between parents when having a child, by mothers age

AGE DIFFERENCE BY AGE OF THE MOTHER

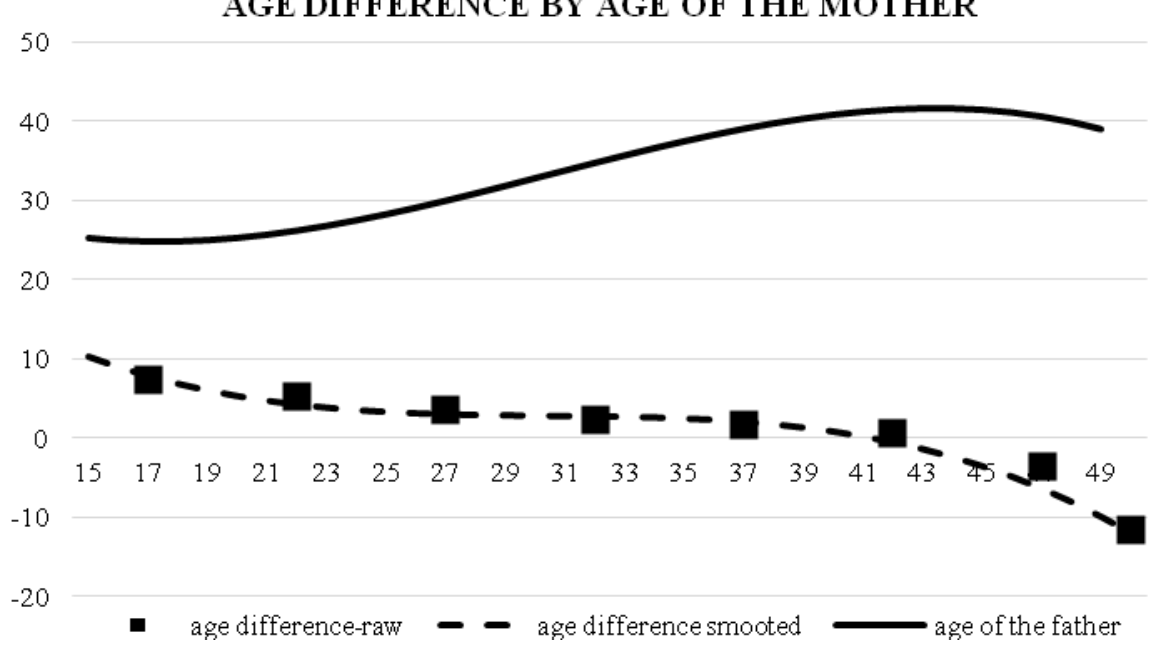

Equation 3: Smoothed age difference - parabolic function (dash type line in Figure 2)

$A D_{x}=-0.0019 x^{3}+0.0936 x^{2}-1.5708 x+11.83$

Values of three mentioned age-specific quantities: $\operatorname{adj} \mathrm{PR}_{\mathrm{x}}, \operatorname{adj}_{\mathrm{x}}$, and $\operatorname{adjLR}_{\mathrm{x}}$ will be calculated as smoothed averages of results from afore mentioned studies discussed in chapter 'Fertility postponement and reproductive outcomes - literature overview', and adjusted to conception timepoint using Equation 1.

Equation 4: Smoothed pregnancy rate - quadratic trend

$P R_{x}=-0.0827 x^{2}+1.7859 x+76.756$

Equation 5: Impregnation rate

$I R_{x}=I R_{x-1} * 0.97$

Equation 6: Smoothed livebirth rate - quadratic trend

$L R_{x}=-0.1137 x^{2}+2.7068 x+76.499$ 
Table 2: Infertility restriction (age-specific pregnancy and impregnation rates) - percentage

\begin{tabular}{|c|c|c|c|c|c|c|c|c|c|c|}
\hline Age & $\begin{array}{c}\text { Dunson et } \\
\text { al. }(2004) \\
\text { two inter- } \\
\text { courses }\end{array}$ & $\begin{array}{c}\text { Wesselink } \\
\text { et al. } \\
\text { (2017) }\end{array}$ & $\begin{array}{l}\text { Steiner and } \\
\text { Jukic } \\
(2016)\end{array}$ & average & $\begin{array}{l}\text { Quadratic } \\
\text { trend }\end{array}$ & $\operatorname{adjPR}_{x}$ & $\begin{array}{c}\mathrm{IR}_{\mathrm{x}} \\
\text { by male } \\
\text { age }\end{array}$ & $\begin{array}{c}\text { Fathers } \\
\text { age-Serbia }\end{array}$ & $\begin{array}{c}\mathrm{IR}_{\mathrm{x}} \text { Serbia } \\
\text { by female } \\
\text { age }\end{array}$ & $\begin{array}{c}\text { adjIR }_{x} \\
\text { Serbia } \\
\text { by female } \\
\text { age } \\
\end{array}$ \\
\hline 15 & & & & & 80.0 & 78.8 & 100.0 & 25.4 & 96.3 & 95.8 \\
\hline 16 & & & & & 81.4 & 80.3 & 100.0 & 25.0 & 97.0 & 96.5 \\
\hline 17 & & & & & 82.6 & 81.7 & 100.0 & 24.9 & 97.3 & 97.1 \\
\hline 18 & & & & & 83.6 & 82.8 & 100.0 & 24.9 & 97.3 & 97.3 \\
\hline 19 & 92 & & & 92.0 & 84.5 & 83.8 & 100.0 & 25.1 & 96.8 & 97.2 \\
\hline 20 & 92 & & & 92.0 & 85.2 & 84.7 & 100.0 & 25.4 & 96.3 & 96.7 \\
\hline 21 & 92 & 70.8 & & 81.4 & 85.8 & 85.3 & 100.0 & 25.8 & 95.7 & 96.2 \\
\hline 22 & 92 & 70.8 & & 81.4 & 86.1 & 85.8 & 100.0 & 26.3 & 94.8 & 95.5 \\
\hline 23 & 92 & 70.8 & & 81.4 & 86.3 & 86.2 & 100.0 & 26.9 & 93.8 & 94.6 \\
\hline 24 & 92 & 70.8 & & 81.4 & 86.4 & 86.4 & 100.0 & 27.6 & 92.7 & 93.5 \\
\hline 25 & 92 & 79.3 & & 85.7 & 86.3 & 86.4 & 97.0 & 28.3 & 91.5 & 92.4 \\
\hline 26 & 92 & 79.3 & & 85.7 & 86.0 & 86.2 & 95.3 & 29.2 & 90.0 & 91.1 \\
\hline 27 & 87 & 79.3 & & 83.2 & 85.5 & 85.9 & 93.7 & 30.1 & 88.5 & 89.6 \\
\hline 28 & 87 & 77.9 & & 82.5 & 84.9 & 85.4 & 92.0 & 31.0 & 87.0 & 88.1 \\
\hline 29 & 87 & 77.9 & & 82.5 & 84.2 & 84.7 & 90.3 & 31.9 & 85.5 & 86.6 \\
\hline 30 & 87 & 77.9 & 87 & 84.0 & 83.2 & 83.9 & 88.7 & 32.9 & 83.8 & 85.1 \\
\hline 31 & 86 & 76.6 & 87 & 83.2 & 82.1 & 82.9 & 87.0 & 33.8 & 82.3 & 83.4 \\
\hline 32 & 86 & 76.6 & 88 & 83.5 & 80.8 & 81.8 & 85.3 & 34.8 & 80.6 & 81.9 \\
\hline 33 & 86 & 76.6 & 88 & 83.5 & 79.4 & 80.5 & 83.7 & 35.7 & 79.1 & 80.3 \\
\hline 34 & 86 & 74.8 & 82 & 80.9 & 77.8 & 79.0 & 82.0 & 36.7 & 77.5 & 78.7 \\
\hline 35 & 82 & 74.8 & 82 & 79.6 & 76.0 & 77.3 & 80.3 & 37.5 & 76.1 & 77.1 \\
\hline 36 & 82 & 74.8 & 76 & 77.6 & 74.1 & 75.5 & 78.6 & 38.3 & 74.8 & 75.8 \\
\hline 37 & 82 & 67.4 & 76 & 75.1 & 72.0 & 73.6 & 77.0 & 39.1 & 73.5 & 74.5 \\
\hline 38 & 82 & 67.4 & 71 & 73.5 & 69.7 & 71.4 & 75.3 & 39.8 & 72.3 & 73.2 \\
\hline 39 & 82 & 67.4 & 71 & 73.5 & 67.3 & 69.1 & 73.6 & 40.4 & 71.3 & 72.1 \\
\hline 40 & & 55.5 & 54 & 54.8 & 64.7 & 66.6 & 72.0 & 40.9 & 70.5 & 71.1 \\
\hline 41 & & 55.5 & 54 & 54.8 & 61.9 & 64.0 & 70.3 & 41.3 & 69.8 & 70.3 \\
\hline 42 & & 55.5 & 48 & 51.8 & 59.0 & 61.2 & 68.6 & 41.5 & 69.5 & 69.7 \\
\hline 43 & & 55.5 & 48 & 51.8 & 55.9 & 58.2 & 67.0 & 41.7 & 69.1 & 69.4 \\
\hline 44 & & 55.5 & & 55.5 & 52.6 & 55.1 & 65.3 & 41.6 & 69.3 & 69.2 \\
\hline 45 & & 55.5 & & 55.5 & 49.2 & 51.8 & 63.6 & 41.5 & 69.5 & 69.3 \\
\hline 46 & & & & & 45.6 & 48.3 & 62.0 & 41.2 & 70.0 & 69.6 \\
\hline 47 & & & & & 41.9 & 44.7 & 60.3 & 40.6 & 71.0 & 70.2 \\
\hline 48 & & & & & 38.0 & 40.9 & 58.6 & 39.9 & 72.1 & 71.3 \\
\hline 49 & & & & & 33.9 & 36.9 & 57.0 & 39.0 & 73.6 & 72.5 \\
\hline
\end{tabular}

Source: Dunson et al., (2004); Steiner and Jukic (2016); Wesselink et al., (2017), and authors calculations

Sociológia 53, 2021, No. 3 
Table 3: Age-specific livebirth rates (percentage)

\begin{tabular}{|c|c|c|c|c|c|c|}
\hline Age & $\begin{array}{c}\text { Nybo-Andersen et al. } \\
(2000)\end{array}$ & $\begin{array}{c}\text { Leridon } \\
\text { (2004) }\end{array}$ & $\begin{array}{c}\text { Schmidt et al. } \\
\text { (2012) }\end{array}$ & -average- & $\begin{array}{l}\text {-quadratic } \\
\text { trend- }\end{array}$ & $\operatorname{adjLR}_{x}$ \\
\hline 15 & 87.4 & & & 87.4 & 81.5 & 79.7 \\
\hline 16 & 87.4 & & & 87.4 & 83.6 & 82.0 \\
\hline 17 & 87.4 & & & 87.4 & 85.5 & 84.1 \\
\hline 18 & 87.4 & & & 87.4 & 87.2 & 85.9 \\
\hline 19 & 87.4 & & & 87.4 & 88.6 & 87.6 \\
\hline 20 & 89.2 & & 90.6 & 89.9 & 89.9 & 89.0 \\
\hline 21 & 89.2 & & 90.6 & 89.9 & 90.9 & 90.1 \\
\hline 22 & 89.2 & & 90.6 & 89.9 & 91.7 & 91.1 \\
\hline 23 & 89.2 & & 90.6 & 89.9 & 92.2 & 91.8 \\
\hline 24 & 89.2 & & 90.6 & 89.9 & 92.5 & 92.3 \\
\hline 25 & 88.1 & 86.4 & 90.6 & 88.4 & 92.6 & 92.5 \\
\hline 26 & 88.1 & 86.4 & 90.6 & 88.4 & 92.5 & 92.6 \\
\hline 27 & 88.1 & 86.4 & 90.6 & 88.4 & 92.1 & 92.4 \\
\hline 28 & 88.1 & 86.4 & 90.6 & 88.4 & 91.5 & 92.0 \\
\hline 29 & 88.1 & 86.4 & 90.6 & 88.4 & 90.7 & 91.3 \\
\hline 30 & 84.5 & 84 & 90.2 & 86.2 & 89.7 & 90.4 \\
\hline 31 & 84.5 & 84 & 90.2 & 86.2 & 88.4 & 89.3 \\
\hline 32 & 84.5 & 84 & 90.2 & 86.2 & 86.9 & 88.0 \\
\hline 33 & 84.5 & 84 & 90.2 & 86.2 & 85.2 & 86.5 \\
\hline 34 & 84.5 & 84 & 90.2 & 86.2 & 83.2 & 84.7 \\
\hline 35 & 75.3 & 80 & 85 & 80.1 & 81.0 & 82.7 \\
\hline 36 & 75.3 & 80 & 85 & 80.1 & 78.6 & 80.4 \\
\hline 37 & 75.3 & 80 & 85 & 80.1 & 76.0 & 77.9 \\
\hline 38 & 75.3 & 80 & 85 & 80.1 & 73.1 & 75.3 \\
\hline 39 & 75.3 & 80 & 85 & 80.1 & 70.0 & 72.3 \\
\hline 40 & 52.5 & 73 & 68 & 64.5 & 66.7 & 69.2 \\
\hline 41 & 52.5 & 73 & 68 & 64.5 & 63.1 & 65.8 \\
\hline 42 & 52.5 & 73 & 68 & 64.5 & 59.4 & 62.2 \\
\hline 43 & 52.5 & 73 & 68 & 64.5 & 55.4 & 58.4 \\
\hline 44 & 52.5 & 73 & 68 & 64.5 & 51.1 & 54.3 \\
\hline 45 & 17.2 & & 45 & 31.1 & 46.7 & 50.0 \\
\hline 46 & 17.2 & & 45 & 31.1 & 42.0 & 45.5 \\
\hline 47 & 17.2 & & 45 & 31.1 & 37.1 & 40.8 \\
\hline 48 & 17.2 & & 45 & 31.1 & 32.0 & 35.8 \\
\hline 49 & 17.2 & & 45 & 31.1 & 26.6 & 30.6 \\
\hline
\end{tabular}

Source: Nybo-Andersen et al., (2000); Leridon, (2004); Schmidt et al., (2012), and authors calculations. 
Table 4: Age-specific success rates (percentage)

\begin{tabular}{|c|c|c|}
\hline Age & Female factor $\left(\operatorname{adjPR} R_{x} * \operatorname{adjLR}\right)$ & $\operatorname{adjSR}_{x}($ age-effect) \\
\hline 15 & 62.8 & 60.2 \\
\hline 16 & 65.9 & 63.6 \\
\hline 17 & 68.7 & 66.7 \\
\hline 18 & 71.2 & 69.3 \\
\hline 19 & 73.4 & 71.3 \\
\hline 20 & 75.3 & 72.8 \\
\hline 21 & 76.9 & 74.0 \\
\hline 22 & 78.2 & 74.6 \\
\hline 23 & 79.1 & 74.8 \\
\hline 24 & 79.7 & 74.5 \\
\hline 25 & 79.9 & 73.8 \\
\hline 26 & 79.8 & 72.7 \\
\hline 27 & 79.3 & 71.1 \\
\hline 28 & 78.5 & 69.2 \\
\hline 29 & 77.4 & 67.0 \\
\hline 30 & 75.9 & 64.6 \\
\hline 31 & 74.1 & 61.8 \\
\hline 32 & 72.0 & 59.0 \\
\hline 33 & 69.6 & 55.8 \\
\hline 34 & 66.9 & 52.7 \\
\hline 35 & 63.9 & 49.3 \\
\hline 36 & 60.7 & 46.0 \\
\hline 37 & 57.3 & 42.7 \\
\hline 38 & 53.7 & 39.3 \\
\hline 39 & 50.0 & 36.0 \\
\hline 40 & 46.1 & 32.8 \\
\hline 41 & 42.1 & 29.6 \\
\hline 42 & 38.1 & 26.5 \\
\hline 43 & 34.0 & 23.6 \\
\hline 44 & 29.9 & 20.7 \\
\hline 45 & 25.9 & 18.0 \\
\hline 46 & 22.0 & 15.3 \\
\hline 47 & 18.2 & 12.8 \\
\hline 48 & 14.6 & 10.4 \\
\hline 49 & 11.3 & 8.2 \\
\hline Average & 66.4 (optimal age 17-34) & 60.02 (optimal age $15-3$ \\
\hline
\end{tabular}

Source: Authors calculations.

Leridon (2004) found that $75 \%$ of women starting to try to conceive naturally at the age of 30 would have a conception ending in a livebirth within 
12-months; this dropped to $66 \%$ at the age of 35 and $44 \%$ at the age of 40 . If we compare these values with our female factor, we can see that the corresponding rates are $79.9 \%, 63.9 \%$ and $46.1 \%$ respectively, very similar but slightly above Leridon's (2004). adjPR $R_{x}$ is highest at age 24-25, and almost halved until the age of 47. Similarly, $a d j L R_{x}$ is highest at the age of $26(92.6 \%)$, and more than halved after the following 20 years of life-time. The female capability of giving birth to the live-child during a year seems to be the highest at the age of 25 (4/5 of all women aged 25 and trying to get pregnant). However, when the male-factor in Serbia is taken into account, we get to the age of 23 of women as a maximum $a d j S R_{x}$ close to $3 / 4$ (Table 4 ).

Figure 3: Age-specific success rate

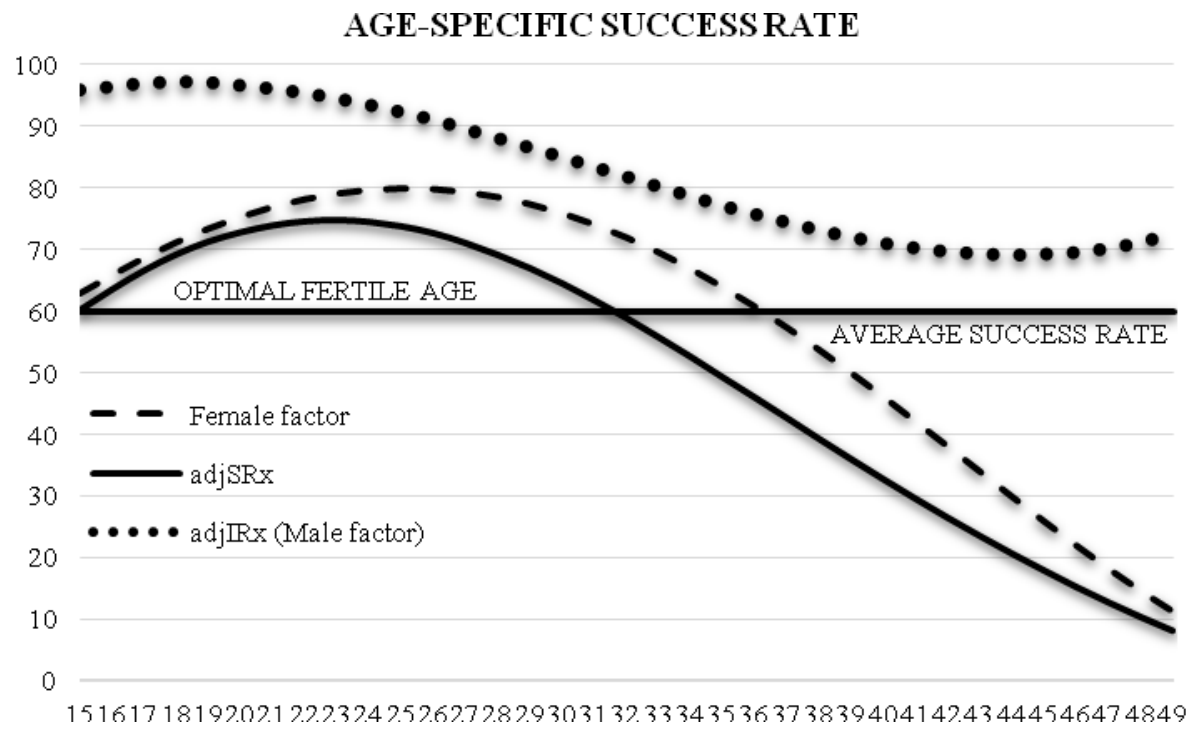

\section{Data and results}

Analysis of changing the age-pattern of fertility on number of livebirths and fertility rates is based on Serbian fertility data. Regarding required data, time series are limited to a period 2001 - 2019. Period data are calculated from Demographic Yearbook of Republic of Serbia, EUROSTAT database, and Human Fertility Database and Collection. During the 19-year time-period, the number of livebirths ${ }^{6}$ was 'rotating' counterclockwise around the age of 30 ,

\footnotetext{
${ }^{6}$ Number of livebirths for years 2001, 2002, 2003, and 2004. is methodologically adjusted to fit other observed data. Until the year 2004. Fertility data included livebirths from women that were abroad (with Serbian citizenship) longer than a year, so we excluded those births.
} 
leading to a rapid decrease of births by mothers below the age of 30 , followed by a slower increase of births by mothers above that age. This change is so deep that in only 19 years, fertility peak shifted 5 years to the right, and rates of women aged $35+$ more than doubled.

Figure 4: Number of livebirths by mother's age in Serbia, 2001 - 2019

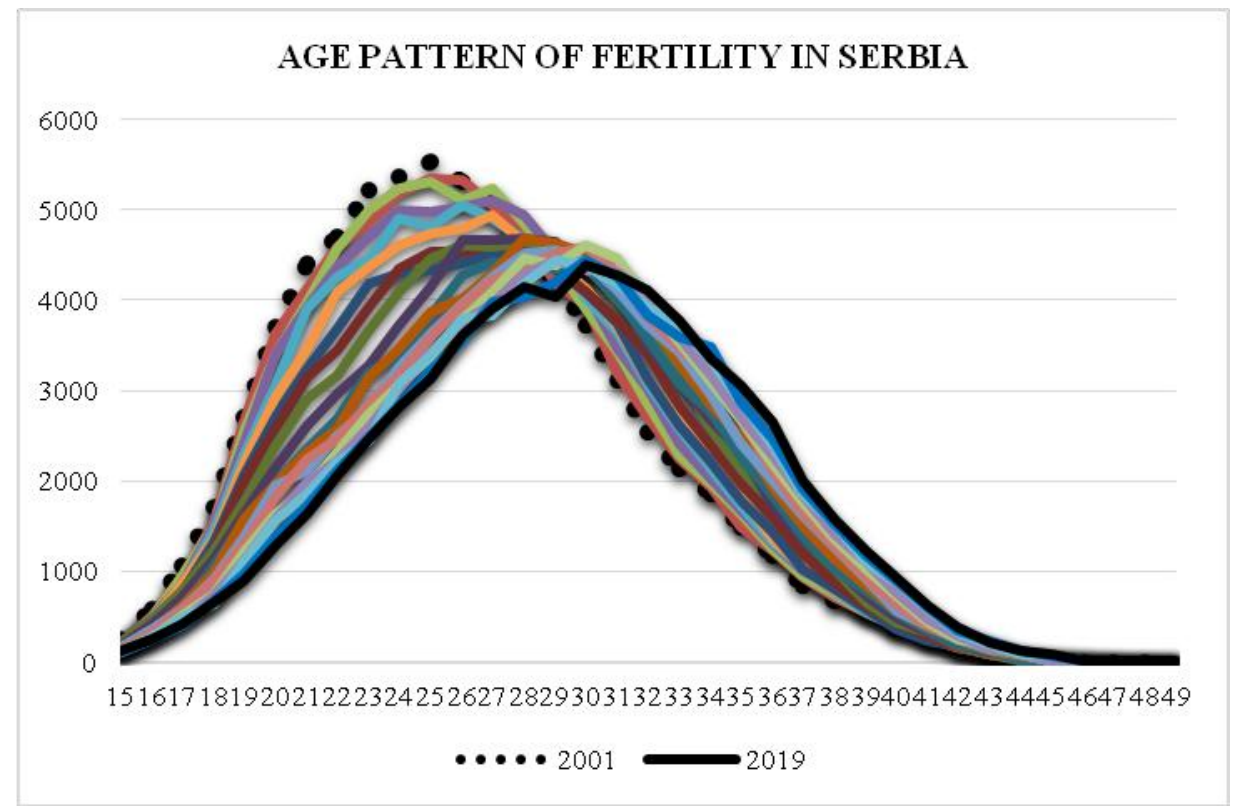

As the livebirths by mother's age are the result of the age-specific adjSR ${ }_{\mathrm{x}}$, then we, by deduction, can come to the number of attempts/women/couples by applying equation 7 .

Equation 7: Age-specific number of women trying to get livebirth

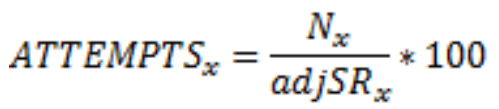

If we compare the first and the last year of the observed period by number of livebirths by mother's age, and number of attempts by age, we can see the whole strength of the age-effect on the number of total livebirths (Figure 5). The number of livebirths decreased by $9186(-12.5 \%)$, but the number of attempts decreased only by $1526(-1.4 \%)$. Through the whole observed timeperiod, the number of attempts remained relatively stable, and ranged between 105915 in 2011 and 113545 in 2003 . With an average of 109860, these values varied between $+3.4 \%$ and $-3.6 \%$ relative to the average, while livebirths 
ranged from 73621 in 2003 to 63778 in 2018 , varying from $+7.7 \%$ to $-6.7 \%$. Fertility postponement depressed average SR, and with the similar number of attempts, women in Serbia gave birth to a much smaller number of children. Age-effect, doubled differences during the observed period.

\section{Figure 5: Comparison of livebirths to attempts}

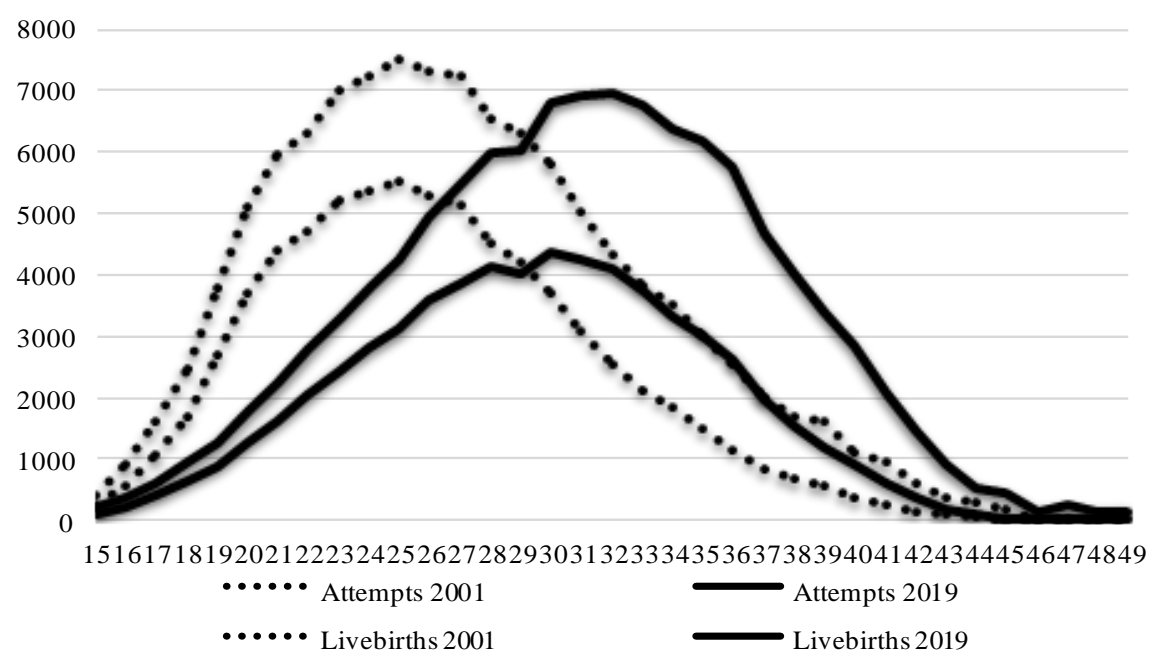

In the Table 5. we showed the number of livebirths and needed attempts to show the change of the age-effect. This relation affects the average SR as the age-pattern of fertility is changing. Maximum TFR (maxTFR) is representing hypothetical case with $100 \%$ adjSR ${ }_{x}$ in all ages. maxTFR can be considered as an estimation of DNC because it reflects the total number of attempts/women wanting to get a live baby during one year. This number isn't affected by induced abortions because they are excluded from an age-model of fertility loss. Medically indicated abortions make up only 5\% share of induced abortions in Serbia (Rašević 2008), so the effect of this eventual oversight would be minimal, and 95\% of induced abortions left are mainly unwanted pregnancies with no influence on DNC. DNC is calculated using number of attempts in each age and estimated number of the women in each age, thus DNC is the sum of age specific fertility rates, only using attempts instead of the livebirths. DNC increases due to a stable number of attempts, and decreasing number of fertile women which, itself, has shrunk from 1,828,130 to 1,510,363. 
Table 5: Livebirths, fertile women, attempts, average adjSR, MAB, TFR, maxTFR/DNC, livebirths lost due to the change of the age-pattern of fertility (2001 baseline), aefTFR ${ }^{7}$, and tempo adjTFR ${ }^{8}$, in Serbia

\begin{tabular}{|c|c|c|c|c|c|c|c|c|c|c|}
\hline Year & Livebirths & $\begin{array}{l}\text { Fertile } \\
\text { women }\end{array}$ & Attempts & $\begin{array}{c}\text { Average } \\
\text { adjSR } \\
(\%)\end{array}$ & MAB & TFR & $\begin{array}{c}\max T F R / \\
D N C\end{array}$ & $\begin{array}{c}\text { Fertility } \\
\text { loss }\end{array}$ & aefTFR & $\begin{array}{r}\text { Tempo } \\
\text { adjTFR }\end{array}$ \\
\hline 2001 & 73352 & 1828130 & 112119 & 65.42 & 26.7 & 1.474 & 2.253 & 0 & 1.474 & 1.474 \\
\hline 2002 & 72969 & 1809136 & 112162 & 65.06 & 26.9 & 1.457 & 2.242 & 411 & 1.465 & 1.822 \\
\hline 2003 & 73621 & 1789668 & 113545 & 64.84 & 27.0 & 1.477 & 2.281 & 664 & 1.490 & 1.641 \\
\hline 2004 & 72734 & 1770053 & 112638 & 64.57 & 27.3 & 1.458 & 2.263 & 958 & 1.477 & 2.083 \\
\hline 2005 & 71768 & 1750845 & 111484 & 64.37 & 27.3 & 1.440 & 2.241 & 1169 & 1.463 & 1.447 \\
\hline 2006 & 70574 & 1733316 & 110154 & 64.07 & 27.5 & 1.419 & 2.220 & 1493 & 1.450 & 1.790 \\
\hline 2007 & 67615 & 1718428 & 105988 & 63.80 & 27.7 & 1.366 & 2.143 & 1726 & 1.400 & 1.724 \\
\hline 2008 & 68559 & 1704735 & 108301 & 63.30 & 27.9 & 1.392 & 2.199 & 2296 & 1.439 & 1.758 \\
\hline 2009 & 69588 & 1691363 & 111041 & 62.67 & 28.2 & 1.421 & 2.265 & 3059 & 1.483 & 2.053 \\
\hline 2010 & 67957 & 1677562 & 109433 & 62.10 & 28.5 & 1.396 & 2.242 & 3638 & 1.471 & 2.016 \\
\hline 2011 & 65211 & 1632708 & 105915 & 61.57 & 28.7 & 1.391 & 2.245 & 4082 & 1.478 & 1.753 \\
\hline 2012 & 66924 & 1615898 & 109495 & 61.12 & 28.9 & 1.441 & 2.339 & 4711 & 1.542 & 1.811 \\
\hline 2013 & 65307 & 1599129 & 107802 & 60.58 & 29.1 & 1.420 & 2.322 & 5221 & 1.534 & 1.786 \\
\hline 2014 & 66144 & 1582643 & 109948 & 60.16 & 29.2 & 1.455 & 2.391 & 5788 & 1.583 & 1.628 \\
\hline 2015 & 65269 & 1566064 & 109166 & 59.79 & 29.5 & 1.451 & 2.396 & 6151 & 1.588 & 2.091 \\
\hline 2016 & 64425 & 1550651 & 108218 & 59.53 & 29.6 & 1.453 & 2.404 & 6375 & 1.597 & 1.623 \\
\hline 2017 & 64718 & 1537044 & 110026 & 58.82 & 29.8 & 1.481 & 2.474 & 7265 & 1.647 & 1.856 \\
\hline 2018 & 63778 & 1523675 & 109315 & 58.34 & 30.0 & 1.480 & 2.488 & 7739 & 1.660 & 1.855 \\
\hline 2019 & 64166 & 1510363 & 110593 & 58.02 & 30.1 & 1.512 & 2.552 & 8188 & 1.705 & 1.736 \\
\hline $\begin{array}{c}\text { Sum/ } \\
\text { Average }\end{array}$ & 1294679 & 1662706 & 109860 & 62.03 & 28.4 & 1.441 & 2.314 & 70934 & 1.523 & 1.806 \\
\hline
\end{tabular}

Source: Authors calculations

If we refer to fertility loss due to the change of the age-pattern, understood as a shift from the baseline age-pattern in 2001, it is obvious that as we 'move' further from the baseline, the fertility loss becomes greater. It can be argued which age-pattern of fertility should be considered as a baseline? By the logic, the natural age-pattern of fertility, understood as a probability distribution of the SR, should be the baseline for measuring the fertility loss. However, our

7 aefTFR (meaning age-effect free TFR) as a possible TFR considering real attempts, but average adjSR from baseline 2001.

8 According to the methodology suggested by Bongaarts and Feeney, 1998 
intention was to identify the fertility decline caused by childbirth postponement in the last two decades, so we set the first observed year as the baseline. During observed time-period, fertility loss rose to 8188 in the 2019, comprising 70934 total livebirths lost throughout the whole time-period. At the same time, TFR ranged from 1.366 to 1.512 with 1.441 on average. If we compare observed TFR with aefTFR ranging from 1.400 to 1.705 with 1.523 on average, we can see that fertility could be $5.7 \%$ higher (on average) in the absence of such agepattern change. Usual way for measuring tempo-effect of fertility postponement is by tempo adjTFR - hypothetical TFR in the absence of MAB increase during one calendar year. Tempo adjTFR during observed period ranged from 1.447 to 2.091 , with 1.806 on average, implying $25.3 \%$ higher TFR in the absence of MAB increase. Our proposed aefTFR does not question the relevance of tempo adjTFR, but is referred only to the biological constraints of fertility, which may be the reason why we identified only $5.7 \%$ of fertility decrease due to childbirth postponement.

\section{Discussion}

Although MAB was rising continuously, the change of the age-pattern of fertility has become more pronounced since 2007 as the fertility bedrock shifted to the upper edge of the optimal reproductive age and negative ageeffect began to rise. Childbirth postponement in Serbia, unfortunately, mostly refers to the first birth postponement to the ages outside the upper age limit of the optimal reproductive period, which often implies frequent unsuccessful attempts, and consequent unrealized fertility intentions (Beaojouan - Toulemon 2021; Castro 2015). Late childbearing in Serbia came into focus in the recent decades, after a long period of below-replacement fertility. Socio-political crisis during 1990's brought childbirth postponement as a most prominent demographic consequence in Serbia, more than the fertility reduction (Rašević 2006). In many countries, the majority of livebirths now take place among women above the age of 30, with Spain having the highest proportion since 2002 (Schmidt et al. 2012). Adequate share in Serbia was 26\% in 2001, and exceeding $51 \%$ in 2019 . Overall rise in MAB leads to completed fertility reduction (Beaujouan et al. 2019; Castro 2015; Schmidt et.al. 2012; d'Albis et al. 2017).

Across some European countries, period TFR started to increase on the upturn of the last century as the pace of fertility postponement was slowing, while many other European populations have exhausted fertility postponement without any significant fertility recuperation. Two possible explanations are: declining reproductive norms that disabled recuperation (d'Albis et. al. 2017; Sobotka 2017), and, stable reproductive norms when translated to advanced ages consequently faced lower realization odds. Even ART-s can't fully 
compensate for the loss of fecundity linked to greater parental age (Schmidt et al. 2012; Eijkemans et al. 2014). ART makes up for only half of the births lost by postponing a first attempt of pregnancy from age 30 to 35 years, and $<30 \%$ after postponing from 35 to 40 years (Leridon 2004). Changes in the agepattern of fertility are important for the explanation of fertility decline in Serbia. Data for 2019 show that births by women of 35+ years have exceeded $20 \%$ of birth total, doubling in the last 12 years. Probability of realizing strong fertility intentions in women is falling from $70 \%$ (around the age of 30 ) to $61 \%$ (around 33 years of age), 48\% around age of 36, and 23\% at age 38-41 (Beaojouan et al. 2019). Associated values of adjSR x $_{x}$ were $65 \%, 56 \%, 46 \%$, and $39-30 \%$ respectively. Obviously adjSR $\mathrm{x}_{\mathrm{x}}$ values closely coincide with the probability of the realization of strong fertility intentions from Beaojouan et.al. (2019), and in some extent leading us to interpret maxTFR as a strongly desired number of children (DNC), because it isn't relying on a declarative statement of couples collected in various socio-demographic surveys, but on estimation of the real number of attempts made.

According to Eurostat, during the last decade, longtime-known trend of relatively high fertility (above 1.7) in North and North-western European (mainly Scandinavian) populations ${ }^{9}$ turned upside-down (except in France). These populations were the examples of successful coexistence of late childbearing and high birth rates. At the same time $(2010-2019)$, post-communist countries ${ }^{10}$ have notably increased period TFR levels. Countries of the northwestern Atlantic rim with strong welfare-states, gender equity and efficient work and family life reconciliation, fell from 1.9 to 1.6 in period TFR, parallel with the rise from 1.5 to 1.6 in post-communist countries, compromising the hitherto fertility divide. Possible explanations can be found in Sobotka (2017): high instability of period indicators which are below the level of replacement, inexistence of obvious threshold of period fertility stabilization, and no lowfertility threshold that makes recovery of fertility impossible. It seems that overall fertility in Europe is far too low, thus every relative change draws attention even if it is absolutely minor. These shifts in period fertility most likely will be smoothed by cohort indicators. However, livebirth swings and causal age-structure distortions can't be neglected.

\footnotetext{
9 Belgium, Denmark, Netherlands, Finland, Sweden and Norway.

${ }^{10}$ Czech Republic, Estonia, Croatia, Latvia, Lithuania, Poland, Slovenia, Slovakia, Serbia, Bulgaria and Romania.
} 
Figure 6: Central and South-Eastern European post-communist countries

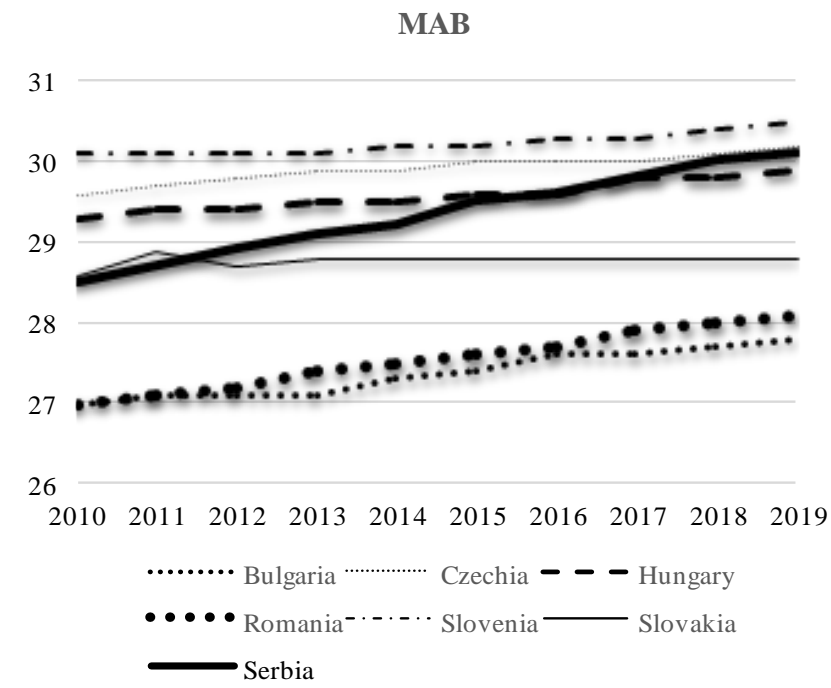

TFR

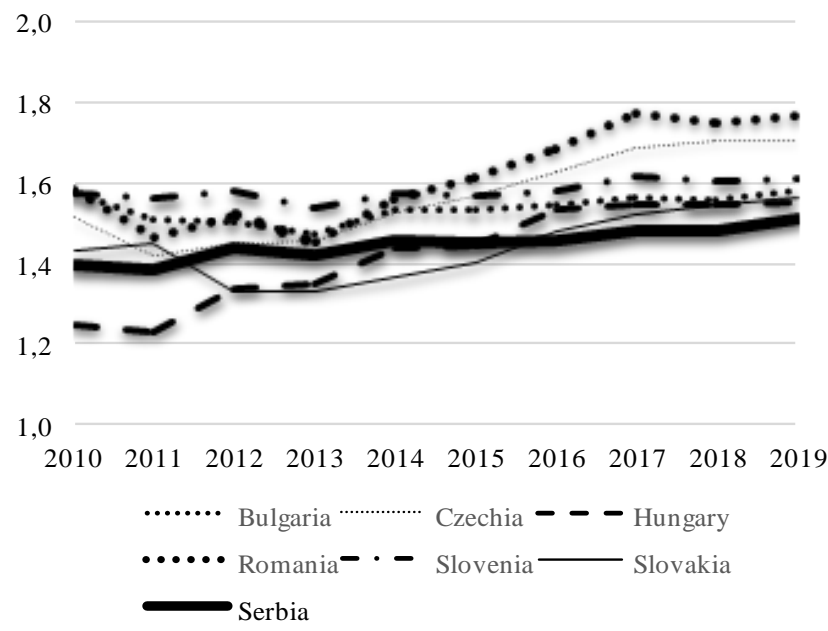

Notably faster pace of fertility postponement in Serbia during the last decade comparing to the other neighboring post-communist countries, surely 
suppressed fertility and disabled Serbia to gain period TFR level as most other post-communist countries did, deepening the gap between TFR and replacement level (Figure 6). During 2001 - 2019 time-period, TFR level was suppressed by 0.082 on average due to the changed age-pattern of fertility, and by 0.365 on average due to the negative tempo-effect (Table 6). Discrepancy between these two may be explained as the share that can be attributed to other, non-biological, effects.

Fertility tempo concept (Bongaarts - Feeney 1998) suggested that certain number of livebirths is translated to the next calendar year to the extent of MAB increase. This concept could be applied in our model, although we can't know, by the MAB increase only, if the births are translated to the next year or to the years to come. That is the main reason why we can't know if the period TFR is suppressed because of the fertility postponement or because of the decline of quantum (Schmidt et al. 2012)? Some reproductive decisions (and livebirths as a result) can be delayed, but can also be reconsidered (and not to happen). Fertility postponement and fertility decline as simultaneous processes are hard to distinguish. The fact that average mother is a bit older in this year than it was in the year before isn't sufficient information for us to conclude about the intensity of birth-delay effect. What if, for example, no woman above the age of 30 gives birth to a child during one year? In that case MAB would decrease and we would still have the fertility postponement. How to interpret it? As a positive tempo-effect, or as a decline of quantum? By the calculation of tempo adjTFR we should conclude that TFR would be even lower without the MAB decrease, which is not true. And again, what if after a certain number of years all women of age 30+ decide to give birth to a child. MAB would inevitably increase, and we, by tempo adjTFR, would conclude that TFR would have been even higher without such MAB increase, which also isn't true. Fertility tempo model presumes that every rise of MAB implies negative tempo-effect, and vice versa. Our model does not. We claim that the age-effect on fertility quantum arises from the age-distribution of attempts, not solely from the MAB. However, our intention wasn't to provide a methodologically sophisticated model, but to initiate a debate on demographic measuring of fertility postponement, and its direct effect on the number of livebirths. Our hypothesis is that final tempo-effect lies only on the age-pattern of fecundity and fetal loss (without questioning reproductive decisions). Reproductive decisions, which are also age-and-parity-related, are a completely different story. The tempo concept actually speculates on future fertility, conversely we have based our model on realized fertility. The main issue in measuring the effect of fertility tempo arises from the fact that future fertility is the unknown variable. It can, but it doesn't have to happen. It is possible that the recuperation in some populations didn't occur because the decline in fertility wasn't the 
result of fertility postponement but of a prevailing reduction of quantum, i.e. the number of attempts. Our effort to identify the number of attempts may be the possible way to successfully understand the differences between populations which have faced fertility recuperation and the ones which have not.

\section{Conclusion}

Fertility postponement largely denotes the childbirth crisis in Serbia during the 21 th century. Some would say that due to a later start of MAB increase, fertility rates in Serbia have yet to rise when birth postponement starts slowing. However, the experience of some countries tells us that such recuperation might never happen. Although Serbia belongs to the group of Eastern European countries (regarding fertility change), it also manifests some societal characteristics of Mediterranean countries, thus we can justifiably suspect if Serbia will recuperate fertility at the same extent as it was suppressed due to childbirth postponement. Albeit the number of attempts remained stable, contemporary age-pattern of fertility made them an insufficient frame for achieving generation replacement. Even with births theoretically distributed within the most fecund ages, replacement of generations isn't achievable. It is clear that the number of attempts (preferred fertility level), altogether with fertility age-pattern should be targeted by the fertility policy. Health recommendations (WHO 2006; USAID and ESD 2007) provide quite suitable bedrock for more enthusiastic introducing of so called 'tempo policies' as an indispensable part of fertility policies (Vasić - Marinković 2016).

Serbia has a generous fertility policy which has been conducted since 2002, although without any significant effect on birth rates. Neglecting natural agedistribution of fecundity and fetal loss leads to a further decline of fertility. The pronatalist strategy of Republic of Serbia in its latest revision, at certain extent, recognized the need of easing couples to start parenthood earlier in life (Ministry of labour and social policy 2018). Straightforward relation of an earlier entrance into parenthood and higher completed fertility has its firm medical, health and demographic foundations. Enabling couples to have children as early as they intend, or even to provide conditions for couples so they don't have to delay parenthood for too long, would yield both an individual and demographic benefit. However, delayed parenthood does not necessarily mean neither childlessness nor few children, but still might bring about happier couples who will be 'catching up' with two or more offspring (Bobić, 2018), if the individual reproductive norms were the fertility policy targets. However, we must not rely entirely on the state, because in the countries of low fertility, the importance of individual reproductive consciousness is far greater than social consciousness, whose influence on the formation of norms on family size is practically non-existent (Rašević 1994). 
A strong desire to have a (subsequent) child only partially compensates for the decline in coital frequency and fecundity with age. This means that the progressive postponement of family formation in modern countries may have a negative effect on the ability to conceive, not only because fecundity declines with age but also because the behavioral component (sexual activity) significantly decreases as well (Rizzi - Rosina 2006).

Petar Vasić - Assistant Professor, has been a lecturer at the Faculty of Geography at University of Belgrade since 2006. His field of scientific interest is demography, and in particular: population policy, population projections, human fertility, and economic demography. He has participated in 4 domestic, and 4 international projects in the fields of population projections, fertility analysis, spatial planning and regional development. He is a member of the Association of Demographers of Serbia, and Serbian Geographical Society.

\section{REFERENCES}

BAIRD, D. D. - STRASSMANN, B. I., 2000: Women's Fecundability and Factors Affecting it. In: Goldman, M. B., Hatch, M. C. (eds.): Women and Health. Pp 126-137. San Diego: Academic Press. https://doi.org/10.1016/B978-012288145-9/50014-0

BEAUJOUAN, E. - REIMONDOS, A. - GRAY, E., 2019: Declining Realisation of Reproductive Intentions with Age. Human Reproduction, Pp. 1-9 https://doi.org/10.1093/humrep/dez150

BEAUJOUAN, E. - SOBOTKA, T., 2017: Late Motherhood in Low-Fertility Countries: Reproductive Intentions, Trends and Consequences. Human Fertility Database Research Report HFD RR-2017-002. https://doi.org/10.1007/978-3-319-14857-1_2

BEAUJOUAN, E. - TOULEMON, L., 2021: European Countries with Delayed Childbearing are not those with Lower Fertility. Genus 77: 2. Springer Open. https://doi.org/10.1186/s41118020-00108-0

BECKER, G., 1965: A Theory of the Allocation of Time. The Economic Journal 75(299): 493517. https://doi.org/10.2307/2228949

BOBIĆ, M., 2018: Transition to Parenthood: New Insights into Socio-Psychological Costs of Chilbearing. Stanovništvo 56(1): 1-25. Belgrade. https://doi.org/10.2298 /STNV180403003B

BONGAARTS, J. - FEENEY, G., 1998: On the Quantum and Tempo of Fertility. Population and Development Review 24(2): 271-291. https://doi.org/10.2307/2807974

CASTRO, R., 2015: Late-Entry-Into-Motherhood Women Are Responsible for Fertility Recuperation. Journal of Biosocial Science 47(2): 275-279. https://doi.org/10.1017/S0021932014000121

D'ALBIS, H. - GREULICH, A. - PONTHIERE, G., 2017: Education, Labour, and the Demographic Consequences of Birth Postponement in Europe. Dem Res: Volume 36, Article 23: 691-728. https://doi.org/10.4054/DemRes.2017.36.23

DUNSON, D. B. - BAIRD, D. D. - COLOMBO, B., 2004: Increased Infertility with Age in Men and Women. Obstet Gynecol 103: 51-56. https://doi.org/10.1097/01.AOG.0000100153.24061.45

EASTERLIN, R., 1969: Towards a Socio-Economic Theory of Fertility: A Survey of Recent Research on Economic Factors in American Fertility. In: Behrman S. J. et al. (eds.): Fertility and Family Planning: A World View. Ann Arbor: University of Michigan Press. Pp. 127156.

Sociológia 53, 2021, No. 3 
EIJKEMANS, M. J. - VAN POPPEL, F. - HABBEMA, J. D. F. et al., 2014: Too Old to have Children? Lessons from Natural Fertility Populations. Hum Reprod 29: 1304-1312. https://doi.org/10.1093/humrep/deu056

FORD, W. C. - NORTH, K. - TAYLOR, H. - FARROW, A. - HULL, M. G. - GOLDING, J., 2000: Increasing Paternal Age is Associated with Delayed Conception in a Large Population of Fertile Couples: Evidence for Declining Fecundity in Older Men. The ALSPAC Study Team (Avon Longitudinal Study of Pregnancy and Childhood). Hum Reprod 15: 1703-1708. https://doi.org/10.1093/humrep/15.8.1703

FREJKA, T. - SARDON, J-P., 2006: First Birth Trends in Developed Countries: Persisting Parenthood Postponement. Demographic Research 15(6): 147-180. https://doi.org/10.4054/DemRes.2006.15.6

HABBEMA, J. D. - EIJKEMANS, M. J. - LERIDON, H. - TE VELDE, E. R., 2015: Realizing a Desired Family Size: When Should Couples Start? Hum Reprod 30: 2215-2221. https://doi.org/10.1093/humrep/dev148

KIDD, S. A. - ESKENAZI, B. - WYROBEK, A. J., 2001: Effects of Male Age on Semen Quality and Fertility: A Review of the Literature. Fertil Steril 75: 237-248. https://doi.org/10.1016/S0015-0282(00)01679-4

LERIDON, H., 2004: Can Assisted Reproduction Technology Compensate for the Natural Decline in Fertility with Age? A Model Assessment. Human Reproduction 19: 1548-1553. https://doi.org/10.1093/humrep/deh304

LESTHAEGHE, R., 2001: Postponement and Recuperation - Resent Fertility Trends and Forecasts in Six Western European Countries. IUSSP Seminar International Perspectives on Low Fertility: Trends, Theories and Policies. Tokyo: Pp. 21-21.

LESTHAEGHE, R., 2010: The Unfolding Story of the Second Demographic Transition. Population and Development Review 36(2). https://doi.org/10.1111/j.1728-4457.2010.00328.x

LIU, K. - CASE, A., 2011: Advanced Reproductive Age and Fertility. SOGC Clinical Practice Guideline. J Obstetric Gynaecol Can. 33(11): 1165-1175.

MAEDA, E. - ISHIHARA, O. - SAITO, H., 2014: Age-Specific Cost and Public Funding of a Live Birth Following Assisted Reproductive Treatment in Japan. Journal of Obstetrics and Gynecology Research 40(5): 1338-1344. https://doi.org/10.1111/jog.12337

MINISTRY OF LABOUR AND SOCIAL POLICY, 2018: The Pronatalist Strategy of the Republic of Serbia. Belgrade.

MODIGLIANI, F. - BRUMBERG, R., 1980: Utility Analysis and Aggregate Consumption Functions: An Attempt at Integration. In A. Abel (ed.): The Collected Papers of Franco Modigliani. MIT Press. Cambridge. Mass.

NYBO-ANDERSEN, A. M. - WOHLFAHRT, J. - CHRISTENS, P. - OLSEN, J. - MELBYE, M., 2000: Maternal Age and Fetal Loss: Population based register linkage study, BMJ 320(7251): 1708-1712. https://doi.org/10.1136/bmj.320.7251.1708

PENEV, G., 1995: Cohort Fertility of Serb and Ethnic Albanian Women in FR Yugoslavia. Stanovništvo XXXIII (1-4): 5-19.

PENEV, G., 2001: Zamena generacija u Srbiji u periodu 1950 - 2000. Stanovništvo XXXIX (14) 45-71. https://doi.org/10.2298/STNV0104045P

PINBORG, A. - GAARSLEV, C. - HOUGAARD, C. O., 2011: Influence of Female Body Weight on IVF Outcome Including Live Birth Rate-a Longitudinal Multi-Centre Cohort Study of 487 infertile couples. RMB Online.

https://doi.org/10.1016/j.rbmo.2011.06.010 
RAŠEVIĆ, M., 1994: Svest i niska plodnost stanovništva. Zbornik radova - Prilozi demografskim i ekonomskim naukama. SANU. Beograd.

RAŠEVIĆ, M., 1995: Prihvatanje populacione politike na individualnom nivou. Stanovništvo 33(1-4): 41-55.

RAŠEVIĆ, M., 2006: Postponing of Childbearing in the Optimal Life Age: A Basic Demographic Consequence of the 1990s in Serbia. Zbornik Matice srpske za društvene nauke. 121: 141-148. https://doi.org/10.2298/ZMSDN0621141R

RAŠEVIĆ, M., 2008: Is the Number of Registered Abortions in Serbia Realistic? Stanovništvo 2: 7-21. https://doi.org/10.2298/STNV0802007R

RAŠEVIĆ, M., 2015: Fertilitet ženskog stanovništva. U Nikitović, V. (ur.): Populacija Srbije na početku 21. veka. RZS Beograd.

RIZZI, E. - ROSINA, A., 2006: Does Sex Matter? Ageing and Ability to Conceive. Vienna Yearbook of Population Research. Pp. 77-90. https://doi.org/10.1553/populationyearbook2006s 77

SCHMIDT, L. - SOBOTKA, T. - BENTZEN, J. G. - NYBO-ANDERSEN, A. M., 2012: Demographic and Medical Consequences of the Postponement of Parenthood. Hum Reprod Update 18: 29-43. https://doi.org/10.1093/humupd/dmr040

SOBOTKA, T., 2011: Fertility in Central and Eastern Europe after 1989: Collapse and Gradual Recovery. Historical Social Research 36(2): 246-296.

SOBOTKA, T., 2017: Post-Transitional Fertility: The Role of Childbearing Postponement in Fueling the Shift to Low and Unstable Fertility Levels. Journal of Biosocial Science 49: S20S45. Cambridge University Press. https://doi.org/10.1017/S0021932017000323

SOBOTKA, T. - SKIRBEKK, V. - PHILIPOV, D., 2011: Economic Recession and Fertility in the Developed World. Population and Development Review 37(2): 267-306. https://doi.org/10.1111/j.1728-4457.2011.00411.x

STANOJEVIĆ, D., 2013: Obeležja društvenog položaja mladih. U Tomanović, S. et.al. (ur): Mladi-naša sadašnjost. Istraživanje socijalnih biografija mladih u Srbiji. Pp. 53-80. Beograd.

STEINER, A. Z. - JUKIC, A. M., 2016: Impact of Female Age and Nulligravidity on Fecundity in an Older Reproductive Age Cohort. Fertil Steril 105: 1584-1588. https://doi.org/10.1016/j.fertnstert.2016.02.028

TESTA, M. R., 2007: Childbearing Preferences. Vienna Yearbook of Population Research pp. 357-379. https://doi.org/10.1553/populationyearbook2007s357

USAID and ESD. 2007. HTSP 101: Everything You Want to Know About Healthy Timing and Spacing of Pregnancy, Washington DC. http://www.who.int/pmnch/topics/maternal/htsp101.pdf

VAN DE KAA, D., 2001: Postmodern Fertility Preference: From Changing Value Orientation to Changing Behavior. Population and Development Review. Vol. 27. Supplement Global Fertility Transition.

VASIĆ, P. - MARINKOVIĆ, I., 2016: Parental Allowance in Serbia - Examining World Health Organizatin Recommendations. Transylvanian Review of Administrative Sciences 49: 150168.

VASIĆ, P., 2017: Novi pristup politici prema rađanju. U Mitrović, Lj., (ur.): Stanovništvo jugoistočne Srbije: Demografski problemi jugoistočne Srbije i mogućnosti izgradnje pronatalitetske nacionalne strategije i politike. Pp 215-226. Niš.

VASIĆ, P. - GLIGORIJEVIĆ, V. - DEVEDŽIĆ, M., 2014: Responding to Population Policy Which Women Can Provide the Greatest Demographic Benefit in Serbia? Zbornik Matice Srpske za društvene nauke. 148: 541-550. https://doi.org/10.2298/ZMSDN1448541V

Sociológia 53, 2021, No. 3 
WESSELINK, A. K. - ROTHMAN, K. J. - HATCH, E. E., 2017: Age and Fecundability in a North American Preconception Cohort Study. Am J Obstet Gynecol 217: 667. https://doi.org/10.1016/j.ajog.2017.09.002

WHO, 2006: Report of a WHO Technical Consultation on Birth Spacing, Geneva: WHO, http://www.who.int/maternal_child_adolescent/documents/birth_spacing. pdf? ua=1

WOMEN AND MEN IN THE REPUBLIC OF SERBIA, 2017: Statistical Office of the Republic of Serbia, Belgrade.

ZEMAN, K. - BEAUJOUAN, E. - BRZOZOWSKA, Z. - SOBOTKA, T., 2018: Cohort Fertility Decline in Low Fertility Countries: Decomposition using Parity Progression Ratios. Demographic Research 38: 651-690. https://doi.org/10.4054/DemRes.2018.38.25

\section{DATA SOURCES}

DEMOGRAPHIC YEARBOOK IN THE REPUBLIC OF SERBIA, RZS. https://www.stat.gov.rs/publikacije/?d=14

EUROSTAT FERTILITY DATABASE https://appsso.eurostat.ec.europa.eu/nui/ show.do?dataset $=$ demo_frate \&lang=en

HUMAN FERTILITY COLLECTION, Max Planck Institute for Demographic Research (MPIDR) and the Vienna Institute of Demography (VID) www.fertilitydata.org

HUMAN FERTILITY DATABASE, Max Planck Institute for Demographic Research and Vienna Institute of Demography. http://www.humanfertility.org.

STATE STATISTICS ADMINISTRATION OF KINGDOM OF SERBIA, 1905: Statistical Yearbook of the Kingdom of Serbia, book VII, State Printing Office of the Kingdom of Serbia, Belgrade. 